\title{
Compound Heterozygous Mutation of Aquaporin 2 Gene in Woman Patient with Congenital Nephrogenic Diabetes Insipidus
}

\author{
Zenta Tsutsumi, Taku Inokuchi, Daisuke Tamada, Yuji Moriwaki, \\ Tsuneyoshi Ka, Sumio Takahashi and Tetsuya Yamamoto
}

\begin{abstract}
We performed mutational analyses of a woman patient with congenital nephrogenic diabetes insipidus referred to us during pregnancy. The diagnosis was made during the neonatal period, after which she was treated with spironolactone and hydrochlorothiazide. Our examination showed the patient to be apparently in good health without definite evidence of dehydration. Serum and urine osmolality were $220 \mathrm{mOsm} / \mathrm{L}$ and 50 $\mathrm{mOsm} / \mathrm{L}$, respectively, and the serum concentration of AVP was $2.7 \mathrm{pg} / \mathrm{mL}$. Results of a water-deprivation test performed after delivery were compatible with nephrogenic diabetes insipidus. Mutational analyses showed that the patient was a compound heterozygote with point mutations at nucleotide position 298 (G to A; G100R) in exon 1 and nucleotide position 374 (C to T; T125M) in exon 2 of the aquaporin 2 gene, which have been previously described.
\end{abstract}

Key words: aquaporin 2 , nephrogenic diabetes insipidus, polyuria

(Inter Med 48: 437-440, 2009)

(DOI: 10.2169/internalmedicine.48.1642)

\section{Introduction}

Nephrogenic diabetes insipidus (NDI) is a rare disease caused by functional defects in the arginine vasopressin (AVP) V2 receptor or aquaporin 2 (AQP2) in the AVPresponsive water channel in collecting tubules of the kidneys. Individuals with the disease are characterized by an inability of the kidneys to concentrate urine in response to AVP $(1,2)$. Although the most common type of NDI is an acquired form, some rare cases are inherited, of which $90 \%$ are caused by mutations of the AVP V2 receptor found on the $\mathrm{X}$ chromosome (3) and $10 \%$ by mutations of the AQP2 water channel located in chromosome region $12 \mathrm{q} 13$ (4). In the present study, we identified a compound heterozygous mutation in the AQP2 gene (G100R and $\mathrm{T} 125 \mathrm{M})$ in a woman patient with congenital NDI.

\begin{tabular}{l} 
Case Report \\
\hline A 27 -year-old woman, who had been diagnosed with NDI \\
after birth during the neonatal period and treated with spiro- \\
nolactone and hydrochlorothiazide, was referred to our divi- \\
sion because pregnancy was evident. Her elder brother was \\
also diagnosed with NDI, however, her family and past his- \\
tories were otherwise not contributory. There was no con- \\
sanguineous marriage by her parents. At the time of consul- \\
tation, the patient was at 7 weeks of gestation, and she had \\
not taken spironolactone and hydrochlorothiazide for 10 \\
months because she hoped to have a baby and the effect of \\
these agents was unsatisfactory to reduce her urine output \\
and improve her QOL. Upon examination, she was appar- \\
ently in good health with a regular pulse rate of 74 beats \\
per minute, respiratory rate of 16 per minute, and blood \\
pressure of 99/69 mmHg. Her height was 160 cm and \\
weight 64.0 kg, and skin turgor was normal. There were no \\
abnormal findings in her chest, abdomen, and extremities,
\end{tabular}

\section{Case Report}

A 27-year-old woman, who had been diagnosed with NDI after birth during the neonatal period and treated with spironolactone and hydrochlorothiazide, was referred to our division because pregnancy was evident. Her elder brother was also diagnosed with NDI, however, her family and past histories were otherwise not contributory. There was no consanguineous marriage by her parents. At the time of consultation, the patient was at 7 weeks of gestation, and she had not taken spironolactone and hydrochlorothiazide for 10 these agents was unsatisfactory to reduce her urine output and improve her QOL. Upon examination, she was apparently in good health with a regular pulse rate of 74 beats per minute, respiratory rate of 16 per minute, and blood weight $64.0 \mathrm{~kg}$, and skin turgor was normal. There were no abnormal findings in her chest, abdomen, and extremities,

Division of Endocrinology and Metabolism, Department of Internal Medicine, Hyogo College of Medicine, Nishinomiya 


\section{GGA(Gly) $\rightarrow$ AGA(Arg)}

\section{G C T G G G G G C T G T G G C C GG A G C C G C T C T G}

\section{Exon 1}

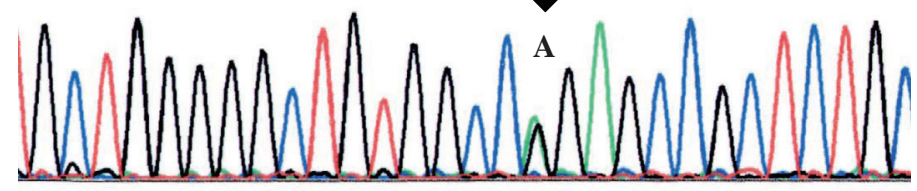

$$
\operatorname{ACG}(\text { Thr }) \rightarrow \text { ATG(Met) }
$$

TCA G C A A CA G C A C G A C G G C T G G C C A G G C G

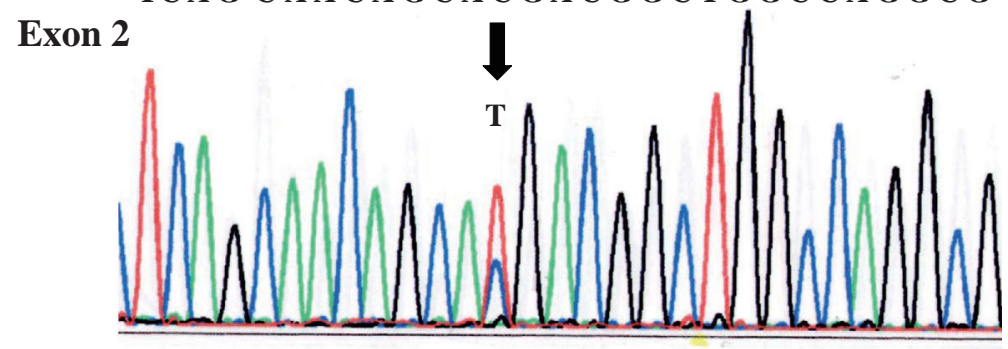

Figure 1. Mutational analyses of exon 1 and 2 of $A Q P 2$ gene of the patient. Arrows indicate heterozygous $G$ and $A$ at nucleotide 298 in exon 1, and heterozygous $C$ and $T$ at nucleotide 374 in exon 2.

though urine output ranged from 5 to 10 L/day during hospitalization. A laboratory examination disclosed the following values: total protein at $5.5 \mathrm{~g} / \mathrm{dL}$, serum sodium at 142 $\mathrm{mmol} / \mathrm{L}$, potassium at $3.8 \mathrm{mmol} / \mathrm{L}$, chloride at $110 \mathrm{mmol} / \mathrm{L}$, and calcium at $9.4 \mathrm{mg} / \mathrm{dL}$. Urine specific gravity was 1.001 . Her basal plasma AVP value was $2.7 \mathrm{pg} / \mathrm{mL}$, with plasma and urine osmolality of $280 \mathrm{mOsm} / \mathrm{L}$ and $50 \mathrm{mOsm} / \mathrm{L}$, respectively. Fasting plasma glucose level was $72 \mathrm{mg} / \mathrm{dL}$ and urinalysis findings were normal. She gave birth to a 3,084 g man infant after a full term. The labor was uneventful and a water-deprivation test performed 5 days later confirmed NDI.

\section{Materials and Methods}

After obtaining written informed consent, mutation analyses of the patient and her family members were performed by direct DNA sequencing of the $A Q P 2$ gene using primers described by Deen et al. (5), as well as for the AVP V2 receptor.

\section{Results}

\section{Mutational analysis}

Our results showed that the patient was a compound heterozygote with two different point mutations in the $A Q P 2$ gene (Fig. 1). We found a $\mathrm{G}$ to $\mathrm{A}$ transversion at nucleotide position 298 in exon 1 and $\mathrm{C}$ to $\mathrm{T}$ transversion at position 374 in exon 2 , resulting in a previously reported mutation at codon 100 (G100R), which is inherited from the father, and a previously reported mutation at codon $125(\mathrm{~T} 125 \mathrm{M})$, inherited from the mother (Fig. 2). These two AQP2 gene mu-

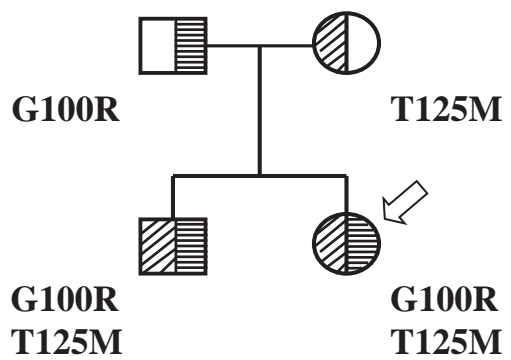

Figure 2. Family pedigree of the patient. The obliqueshaded portion shows a heterozygote for theT125M mutation, while the horizontal-shaded portion shows the G100R mutation. The patient (arrow) and her elder brother were both compound heterozygotes with the T125 and G100R mutations.

tations were confirmed by results of restriction analysis (Fig. 3).

\section{Discussion}

AVP binds to specific V2 receptors on the basolateral membrane of principal cells that comprise the collecting ducts of the kidneys, thus stimulating adenylcyclase to increase cellular c-AMP via GTP-binding protein Gs. C-AMP activates protein kinase $\mathrm{A}$ and protein phosphorylation, leading to a shift in the localization of AQP2, a 29-kDa hydrophobic glycoprotein that functions as an AVP-responsive water channel in principal cells, from intracellular vesicles to the apical membrane, thereby facilitating transcellular water transport (6-8). As a result, NDI is classified as a functional defect in the AVP V2 receptor in $90 \%$ of the cases and that of AQP2 in the other $10 \%$. Understanding of 


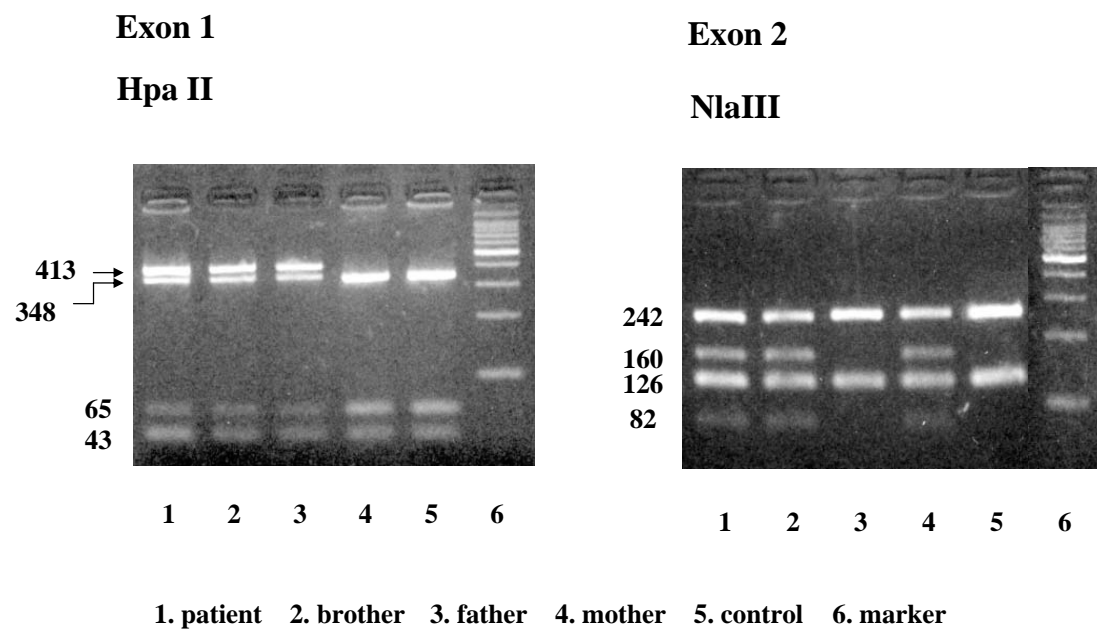

Figure 3. Restriction analysis of mutations of $A Q P 2$ gene. PCR products of exon 1 and 2 were digested with Hpa II and Nla III and separated on a $1 \%$ agarose gel. Resulting fragment length are given in base pairs.

the molecular mechanism of NDI has advanced significantly in recent years. However, at the time of writing, only 39 mutations of the $A Q P 2$ gene have been reported, 28 of which are autosomal recessive and missense point mutations (9). Affected patients are either homozygous for a mutation in the $A Q P 2$ gene or carry two different mutations resulting in compound heterozygosity. We report here an NDI patient with compound heterozygosity with two recurrent missense mutations, G100R and T125M, in the AQP2 gene. To date, a G100R mutation in the $A Q P 2$ gene has been described in Arab families (10), while the T125M mutation has been reported in a Japanese case $(11,12)$.

The father of the present patient possessed a point mutation of G100R in exon 1, while her mother possessed a point mutation of $\mathrm{T} 125 \mathrm{M}$ in exon 2 , and neither showed any manifestations of diabetes insipidus. In addition, her elder brother, who had NDI, possessed the same mutations of the $A Q P 2$ gene as the patient.

The relationships between $A Q P 2$ gene mutations and its function have not been completely elucidated. However, misfolding of the protein and retention in the endoplasmic reticulum (ER) have been reported in most $A Q P 2$ gene mutations (13-18), except for those of T125M and G175R, in which a disrupted water channel function is indicated (11). A functional expression study of the mutated $A Q P 2$ gene using Xenopus oocytes was not performed in the present case. Nevertheless, the mutation of G100R in exon 1 seen in our patient was considered to disturb AQP 2 function, since specific evidence that supports G100R in the AQP2 gene as the disease-causing mutation is provided by other researchers (15), who performed functional expression studies of G100 $\mathrm{V}$ in Xenopus oocytes which showed little increase in water permeability when injected with the associated cRNA. Therefore, compound heterozygosity for G100R and T125M was considered to be responsible for the present case of NDI.

Identification of genetic mutations in individual patients may contribute to early diagnosis of NDI as well as genetic counseling. Such information would be helpful for initiating early intervention to reduce morbidity and understanding the molecular mechanisms related to the function of aquaporin 2 .

\section{Acknowledgement}

The authors are grateful to Ms. Asako Yamamoto for her skillful technical assistance.

\section{References}

1. Bichet DG, Oksche A, Rosenthal W. Congenital nephrogenic diabetes insipidus. J Am Soc Nephrol 8: 1951-1958, 1997.

2. Knoers NV, Monnens LL. Nephrogenic diabetes insipidus. Semin Nephrol 19: 344-352, 1999.

3. Morello JP, Bichet DG. Nephrogenic diabetes insipidus. Annu Rev Physiol 63: 607-630, 2001.

4. Van Os $\mathrm{CH}$, Deen PM. Aquaporin-2 water channel mutations causing nephrogenic diabetes insipidus. Proc Assoc Am Physicians 110: 395-400, 1998.

5. Deen PM, Verdijk MAJ, Knoers NVAM, et al. Requirement of human renal water channel aquaporin-2 for vasopressin-dependent concentration of urine. Science 264: 92-95, 1994.

6. Kuwahara M, Fushimi K, Terada Y, et al. cAMP-dependent phos- phorylation stimulates water permeability of aquaporin-collecting duct water channel protein expressed in Xenopus oocytes. J Biol Chem 270: 10384-10387, 1995.

7. Sasaki S, Fushimi K, Ishibashi K, et al. Water channels in the kidney collecting duct. Kidney Int 1995 48: 1082-1087, 1995.

8. Katsura T, Gustafson C, Ausiello D, et al. Protein kinase A phosphorylation is involved in regulated exocytosis of aquaporin-2 in transfected LLC-PK1 cells. Am J Physiol 272: F817-F822, 1997.

9. Loonen AJM, Knoerrs NVAM, van Os $\mathrm{CH}$, et al. Aquaporin 2 mutations in nephrogenic diabetes insipidus. Semin Nephrol 28 : 252-265, 2008.

10. Carroll P, Al-Mojalli H, Al-Abbad A, et al. Novel mutations underlying nephrogenic diabetes insipidus in Arab families. Genet 
Med 8: 443-447, 2006.

11. Goji K, Kuwahara M, Gu Y, et al. Novel mutations in aquaporin-2 gene in female siblings with nephrogenic diabetes insipidus: evidence of disrupted water channel function. J Clin Endocrinol Metab 83: 3205-3209, 1998.

12. Kuwahara M. Aquaporin-2, a vasopressin-sensitive water channel, and nephrogenic diabetes insipidus. Intern Med 37: 215-217, 1998.

13. Deen PMT, Croes H, van Aubel RAMH, et al. Water channels encoded by mutant aquaporin-2 genes in nephrogenic diabetes insipidus are impaired in their cellular routing. J Clin Invest 95: 2291-2296, 1995.

14. Tamarappoo BK, Yang B, Verkman AS. Misfolding of mutant aquaporin-2 water channels in nephrogenic diabetes insipidus. $\mathrm{J}$ Biol Chem 274: 34825-34831, 1999.
15. Lin SH, Bichet DG, Sasaki S, et al. Two novel aquaporin-2 mutations responsible for congenital nephrogenic diabetes insipidus in Chinese families. J Clin Endocrinol Metab 87: 2694-2700, 2002.

16. Mulders SM, Knoers NV, van Lieburg AF, et al. New mutations in the AQP2 gene in nephrogenic diabetes insipidus resulting in functional but misrouted water channels. J Am Soc Nephrol 8: 242-248, 1997.

17. Rocha JL, Friedman E, Boson W, et al. Molecular analyses of the vasopressin type 2 receptor and aquaporin-2 genes in Brazilian kindreds with nephrogenic diabetes insipidus. Hum Mutat 14: 233-239, 1999.

18. Vargas-Poussou R, Forestier L, Dautzenberg MD, et al. Mutations in the vasopressin V2 receptor and aquaporin-2 genes in 12 families with congenital nephrogenic diabetes insipidus. J Am Soc Nephrol 8: 1855-1862, 1997.

(C) 2009 The Japanese Society of Internal Medicine http://www.naika.or.jp/imindex.html 